DOI: https://doi.org/10.17648/2238-037X-trabedu-v29n1-16240

(c) (1) https://creativecommons.org/licenses/by/4.0/

\title{
Transformações no Mundo do Trabalho e Política Pública EDUCACIONAL NO BRASIL ${ }^{1}$ \\ Changes in the world of work and educational public policy in Brazil
}

SIQUEIRA, Leonardo Moura L. C. $\mathrm{de}^{2}$ SOUZA, Laumar Neves de 3

\section{Resumo}

O presente artigo objetiva questionar a proposta de investimento em capital humano como uma solução para o iminente desemprego estrutural decorrente da adoção das novas tecnologias da robótica e da inteligência artificial publicada em 2018 pelo Banco Mundial. Tendo por base (1) a análise empírica do mercado de trabalho brasileiro a partir da perspectiva da evolução das credenciais educacionais da classe trabalhadora, (2) os impactos das novas tecnologias sobre o trabalho e (3) os desafios decorrentes das metamorfoses vivenciadas pela classe-que-vive-do-trabalho, o artigo conclui ser oportuna a reflexão sobre uma alternativa de política pública educacional que tenha por propósito o desenvolvimento de uma compreensão crítica da sociedade brasileira, levando em consideração não apenas a formação para o trabalho, mas, também para a atuação social e política.

Palavras-chave: Trabalho. Educação. Política Pública.

\section{ABSTRACT}

This article aims to question the World Bank proposal published in 2018 of investment in human capital as a solution to the imminent structural unemployment resulting from the adoption of new technologies of robotics and artificial intelligence. Based on (1) the empirical analysis of the Brazilian labor market from the perspective of the evolution of the working class's educational credentials, (2) the impacts of new technologies on work and (3) the challenges arising from the metamorphoses experienced by the working class, the article concludes that it is opportune to reflect on an alternative of educational public policy that aims to develop a critical understanding of Brazilian society, taking into account not only the training for work, but, also for social and political action.

Keywords: Labor. Education. Public Policy.

\footnotetext{
${ }^{1}$ Parcela significativa deste artigo deriva da pesquisa de mestrado realizada pelo seu autor principal sob a orientação do seu segundo autor e viabilizada graças à bolsa de estudos cedida pela CAPES ao pesquisador no período do curso, de abril/2016 a março/2018.

${ }^{2}$ Doutorando em Economia pela Universidade Federal da Bahia (UFBA). Mestre em Desenvolvimento Regional e Urbano pelo Programa de Pós-Graduação em Desenvolvimento Regional e Urbano da UNIFACS. Graduado em Economia pela UNIFACS. E-mail: leonardo.moura@gmail.com

${ }^{3}$ Doutor em Ciências Sociais pela Universidade Federal da Bahia (UFBA). Possui mestrado e graduação em Economia pela UFBA. Professor titular do Programa de Pós-Graduação em Desenvolvimento Regional e Urbano da UNIFACS. E-mail: laumar.souza@unifacs.br
} 


\section{INTRODUÇÃO}

No final de 2018, o Banco Mundial, no seu periódico Relatório do Desenvolvimento Mundial (World Development Report ou WDR), intitulado "A Natureza Mutante do Trabalho", apresenta seu ponto de vista acerca das políticas públicas a serem adotadas pelos governos, com vistas a preparar suas populações para as transformações iminentes no mundo do trabalho, decorrentes da integração das novas tecnologias da inteligência artificial e da robótica na produção de bens e serviços. Buscando conferir matiz tranquilizador sobre o futuro da classe trabalhadora, o documento classifica como infundadas as preocupações com tais mudanças, apontando para a criação de novos tipos de trabalho para os quais as políticas públicas do campo técnico educacional devem qualificar as pessoas. Investing in human capital is the priority to make the most of this evolving economic opportunity (Banco Mundial, 2018, p. 3).

Com vistas a contribuir para este debate, o presente artigo objetiva questionar a proposta do Banco Mundial e apresentar um possível embrião de ideia de política pública educacional a ela alternativa. A construção deste se dá ao longo do texto, tendo por base três processos: (1) a análise da inserção dos trabalhadores brasileiros no mercado de trabalho do país a partir da perspectiva das credenciais educacionais destes trabalhadores, por meio dos dados do IBGE na Pesquisa Nacional por Amostra de Domicílios (PNAD), para o período compreendido entre 2001 a 20154; (2) a visão apresentada por Teles e Caldas (2019) acerca dos impactos sobre o trabalho decorrentes da adoção de novas tecnologias; e (3) o debate estabelecido entre Filgueiras e Cavalcante (2019) e Standing (2015) sobre as transformações atuais do mundo do trabalho.

Espelhando esta rota metodológica, o artigo está estruturado em três partes além desta introdução e das considerações finais. Na primeira, são identificadas as principais transformações da força de trabalho do Brasil na perspectiva da sua qualificação mediante a conclusão de anos de estudos entre os anos de 2001 a 2015 . Busca-se nessa parcela mais longa do texto identificar em que medida, como apregoado pela Teoria do Capital Humano, a expectativa de melhor inserção no Mundo do Trabalho foi atendida em função da elevação das credenciais educacionais dos trabalhadores brasileiros. Está dividida em cinco subpartes: (a) análise panorâmica da evolução da população economicamente ativa $(\mathrm{PEA})^{5}$; (b) comportamentos dos seus dois subconjuntos - ocupados e desocupados; (c) população ocupada, de acordo com as cinco mais importantes posições na ocupação (empregado, doméstico, conta própria, empregador e não remunerado); (d) o processo de flexibilização das formas de contratação do trabalho; e (e) evolução da remuneração do trabalho.

$\mathrm{Na}$ segunda parte, discute impactos verificados e impactos temidos sobre o trabalho decorrentes da adoção de novas tecnologias. Na terceira seção, apresenta-se, com base no debate travado sobre um suposto novo adeus ao trabalho, como os argumentos

\footnotetext{
${ }^{4}$ Como a metodologia mais nova da Pesquisa Nacional de Amostra por Domicílio (PNAD Contínua) somente passou a ser aplicada aos dados levantados a partir de 2012, escolheu-se trabalhar com a série histórica da PNAD do período de 2001 a 2015, que abrange um recorte temporal mais amplo.

${ }^{5}$ Existem novas nomenclaturas definidas no âmbito da Organização Internacional do Trabalho durante a $19^{a}$ Conferência Internacional dos Estatísticos do Trabalho, realizada em 2013 e que já foram adotadas pela PNAD Contínua. Entretanto, com vistas à manutenção do rigor conceitual, foi imperativa a adoção das categorias da PNAD (ver Pesquisa Nacional por Amostra de Domicílios - Notas metodológicas, disponível em:

ftp://tp.ibge.gov.br/Trabalho_e_Rendimento/Pesquisa_Nacional_por_Amostra_de_Domicilios_anual/microdados/2015/Metodologia_2017 0517.zip).
} 
apresentados fortalecem a retórica sobre a necessidade de desregulamentação do trabalho.

\section{Mercado de trabalho e credenciais educacionais da força de TRABALHO NO BRASIL}

Ao longo das últimas três décadas, o mercado de trabalho brasileiro tem passado por transformações, pari passu com mudanças vivenciadas nos planos da economia e da política do país que, a partir dos anos 1990, acelerou seu processo de integração aos sistemas produtivo e financeiro globais (ALVES, 2007; ANTUNES, 2005; POCHMANN, 2002 e 2008). Impulsionada pelas ondas de desemprego vivenciadas nesse período, a competição entre os trabalhadores na cata pelas melhores oportunidades de inserção, fenômeno típico de conjunturas dessa natureza, previsto por Offe e Hinrichs (1989, p. 61-66), se intensificou, fortalecendo-se a busca da qualificação por meio do estudo como uma estratégia competitiva de diferenciação da mão de obra. De fato, uma das maiores alterações que pode ser destacada no mercado de trabalho nacional é o incremento do tempo de dedicação aos estudos por parte dos indivíduos da população trabalhadora, fenômeno que, como ver-se-á por meio dos dados que aqui são analisados, se processou especificamente nos primeiros quinze anos do século XXI.

\subsection{Panorama da força de trabalho no Brasil nos anos recentes}

Ao se analisar os dados da PNAD referentes à classificação dos grandes subconjuntos populacionais brasileiros em relação ao mercado de trabalho, observa-se que a PEA apresentou um crescimento de $24,3 \%$ entre 2001 e 2015 (Tabela 1). Por ser tal aumento menor que o verificado no subconjunto que a contém (a População em Idade Ativa PIA), a taxa de participação para o referido período caiu $1,8 \%$, saindo de $60,5 \%$ para 59,4\%. Entretanto, avaliando-se o espaço de tempo em fragmentos de 5 (ou 6 anos, entre 2009 e 2015), observa-se crescimento entre 2001 e 2005 (4,0\%), leve redução de 2005 a $2009(1,3 \%)$ e, a partir de 2009 uma queda mais acelerada, que até 2015 é de $4,3 \%$, contrariada, em 2014 , quando o indicador cresceu $2,2 \%$ em relação ao ano anterior (Tabela 1).

Tabela 1 - Evolução da distribuição populacional em relação ao mercado de trabalho - Brasil, 2001, 2005, 2009 e 2015

\begin{tabular}{|c|c|c|c|c|c|c|c|c|}
\hline \multirow{2}{*}{ Ano } & \multicolumn{6}{|c|}{ Populações } & \multirow{2}{*}{ TX. Part. } & \multirow{2}{*}{$\begin{array}{c}\text { Tx. } \\
\text { Desocup. }\end{array}$} \\
\hline & Total & PIA & PNEA & PEA & Ocupados & Desocupados & & \\
\hline 2001 & 172.742 .385 & 140.404 .412 & 55.518 .148 & 84.886 .264 & 76.936 .438 & 7.949 .826 & $60,5 \%$ & $9,4 \%$ \\
\hline 2002 & 175.076 .603 & 143.121 .597 & 55.371 .774 & 87.749 .823 & 79.708.522 & 8.041 .301 & $61,3 \%$ & $9,2 \%$ \\
\hline 2003 & 177.360 .349 & 145.742 .796 & 56.258 .084 & 89.484 .712 & 80.775 .414 & 8.709 .298 & $61,4 \%$ & $9,7 \%$ \\
\hline 2004 & 183.439 .253 & 150.845 .950 & 57.282 .163 & 93.563 .787 & 85.245 .933 & 8.317 .854 & $62,0 \%$ & $8,9 \%$ \\
\hline 2005 & 185.651 .425 & 153.722 .254 & 57.040 .208 & 96.682 .046 & 87.695 .271 & 8.986.775 & $62,9 \%$ & $9,3 \%$ \\
\hline 2006 & 187.851 .823 & 156.758 .044 & 58.898 .251 & 97.859 .793 & 89.636 .973 & 8.222 .820 & $62,4 \%$ & $8,4 \%$ \\
\hline 2007 & 189.953 .924 & 159.411 .395 & 60.512 .220 & 98.899 .175 & 90.854 .655 & 8.044 .520 & $62,0 \%$ & $8,1 \%$ \\
\hline 2008 & 191.999 .849 & 162.266 .233 & 61.679 .940 & 100.586 .293 & 93.420 .362 & 7.165 .931 & $62,0 \%$ & $7,1 \%$ \\
\hline 2009 & 193.995 .123 & 164.640 .165 & 62.359 .292 & 102.280 .873 & 93.783 .537 & 8.497 .336 & $62,1 \%$ & $8,3 \%$ \\
\hline 2011 & 197.825 .297 & 169.211 .451 & 67.625 .798 & 101.585 .653 & 94.763 .220 & 6.822 .433 & $60,0 \%$ & $6,7 \%$ \\
\hline 2012 & 199.688 .907 & 171.035 .897 & 68.572 .836 & 102.463 .061 & 96.100 .290 & 6.362.771 & $59,9 \%$ & $6,2 \%$ \\
\hline 2013 & 201.467 .084 & 173.132 .594 & 69.731 .130 & 103.401 .464 & 96.659 .379 & 6.742 .085 & $59,7 \%$ & $6,5 \%$ \\
\hline 2014 & 203.190 .852 & 175.234 .405 & 68.409 .995 & 106.824 .410 & 99.447 .612 & 7.376 .798 & $61,0 \%$ & $6,9 \%$ \\
\hline 2015 & 204.860 .101 & 177.656 .822 & 72.137 .391 & 105.519.431 & 95.380 .483 & 10.138 .948 & $59,4 \%$ & $9,6 \%$ \\
\hline
\end{tabular}

Fonte: Pesquisa Nacional por Amostra de Domicílio (PNAD/BGE), 2001-2009 e 2011-2015 
Essas variações observadas na taxa de participação resultaram das mudanças de cenário do mercado de trabalho que, por sua vez, refletiram a dinâmica da economia do país. Assim foi que, em períodos de retração ou de baixa dinâmica econômica, como entre 2001 e 2003, observou-se a manutenção de elevadas taxas de desemprego e um concomitante aumento da taxa de participação, que representa a pressão demográfica sobre o mercado de trabalho (Tabela 1). O período de maior crescimento da taxa de participação, entre 2001 e 2005, corresponde ao mesmo em que a taxa de desocupação se manteve em patamares mais elevados. Com efeito, apenas à medida que a desocupação apresentou quedas sucessivas a partir de 2006, ou seja, depois que a economia consolida seguidos incrementos reais, é que se verificou redução na taxa de participação (Tabela 1).

Lançando o olhar sobre esta força de trabalho a partir do ponto de vista da sua distribuição por faixas de anos de estudo, a evolução dos seus números evidencia uma intensa busca por elevação de escolaridade por parte da força de trabalho. Em 2001, as duas classes com menor tempo de estudo somada à daqueles sem instrução, ou seja, o contingente de indivíduos que finalizaram no máximo os sete anos iniciais do sistema formal de ensino perfazia mais da metade da PEA (54,1\%), enquanto as duas últimas, ou seja, a dos indivíduos com onze anos ou mais de estudo compunham $28,6 \%$ da PEA. Em 2015, essa realidade praticamente se inverteu. Isso porque, o primeiro grupo passou a corresponder a $31,2 \%$ da PEA e aquele com maiores credenciais educacionais crescera para mais da metade da força de trabalho, somando 51,5\% desta (Tabela 2).

Tabela 2- Evolução da distribuição da PEA e da taxa de participação por faixas de anos de estudo, Brasil - 2001, 2005, 2009 e 2015

\begin{tabular}{|c|c|c|c|c|c|c|c|c|}
\hline \multirow{2}{*}{ Variável / Cate goria } & \multicolumn{2}{|c|}{2001} & \multicolumn{2}{|c|}{2005} & \multicolumn{2}{|c|}{2009} & \multicolumn{2}{|c|}{2015} \\
\hline & Dist. PEA & Tx. Part. & Dist. PEA & Tx. Part. & Dist. PEA & Tx. Part. & Dist. PEA & Tx. Part. \\
\hline Anosde Estudo & $100,0 \%$ & $60,5 \%$ & $100,0 \%$ & $62,9 \%$ & $100,0 \%$ & $62,1 \%$ & $100,0 \%$ & $59,4 \%$ \\
\hline Sem Instrução & $11,1 \%$ & $52,9 \%$ & $9,1 \%$ & $52,6 \%$ & $7,5 \%$ & $48,0 \%$ & $5,7 \%$ & $39,8 \%$ \\
\hline De 1 a 3 anos & $13,5 \%$ & $49,4 \%$ & $11,2 \%$ & $50,0 \%$ & $8,9 \%$ & $43,7 \%$ & $6,4 \%$ & $37,3 \%$ \\
\hline De 4 a 7 anos & $29,5 \%$ & $53,9 \%$ & $26,8 \%$ & $54,0 \%$ & $23,1 \%$ & $51,2 \%$ & $19,1 \%$ & $45,8 \%$ \\
\hline De 8 a 10 anos & $16,9 \%$ & $65,2 \%$ & $17,4 \%$ & $66,8 \%$ & $17,2 \%$ & $64,9 \%$ & $17,3 \%$ & $59,7 \%$ \\
\hline De 11 a 14 anos & $21,9 \%$ & $78,1 \%$ & $27,6 \%$ & $80,5 \%$ & $33,0 \%$ & $80,1 \%$ & $37,7 \%$ & $76,3 \%$ \\
\hline 15 ou mais anos & $6,7 \%$ & $85,3 \%$ & $7,6 \%$ & $85,6 \%$ & $10,1 \%$ & $85,1 \%$ & $13,8 \%$ & $82,0 \%$ \\
\hline Não determinado & $0,4 \%$ & $70,3 \%$ & $0,3 \%$ & $73,1 \%$ & $0,2 \%$ & $70,4 \%$ & $0,1 \%$ & $62,2 \%$ \\
\hline Não informado & $0,0 \%$ & - & $0,0 \%$ & - & $0,0 \%$ & - & $0,0 \%$ & \\
\hline
\end{tabular}

Fonte: Pesquisa Nacional por Amostra de Domicílio (PNAD/IBGE), 2001-2009 e 2011-2015

Internamente também, no âmbito dos indivíduos com menor tempo de estudo, eles, paulatinamente, entre 2001 e 2015, passaram a ingressar em quantidade relativamente menor no mercado de trabalho. Tal fato pode ser observado na queda de $24,9 \%$ na taxa de participação dos indivíduos sem instrução, que reduziu de 52,9\% para 39,8\%, e na baixa de $24,5 \%$ deste indicador para os indivíduos com tempo de estudo de 1 a 3 anos que decresceu de 49,4\% para 37,3\%. Ou seja, intensificou-se por parte das pessoas em idade ativa a opção por ingressar no mercado de trabalho à medida que ampliavam seu tempo de estudo acumulado. Este processo ainda foi corroborado, a partir principalmente de 2005, pela melhoria na dinâmica econômica do país, que entre este ano e o de 2011 cresceu em média (3,95\% a.a.), fato esse que trouxe reflexos positivos sobre o nível de ocupação. 


\subsection{Evolução da (des)ocupação segundo o tempo de estudo}

Sob o aspecto do tempo de estudo, é comum se pensar que quanto mais um indivíduo se dedica aos estudos, maiores e melhores são suas oportunidades de inserção no mercado de trabalho. Esse raciocínio, quando testado com base nos dados da taxa de desocupação brasileira no período de 2001 a 2015, se mostra apenas parcialmente verdadeiro, já que, dentre as três faixas com maior tempo de estudo, apenas no conjunto da força de trabalho de indivíduos com quinze anos ou mais de formação a taxa de desemprego se fez menor que a taxa geral de desocupação (Gráfico 1). Em relação à taxa verificada em 2001, para o estrato com maiores credenciais escolares, a desocupação cresceu 32,4\%, saltando de 3,7\% para 4,9\% em 2015.

Considerando que, atualmente, o sistema de educação formal define o tempo mínimo do ensino fundamental em nove anos e o do ensino médio, mais três, para entrar neste estrato da PEA, em que a desocupação se faz menor, um indivíduo precisa fazer um curso de nível superior. Entre aqueles que venceram de 8 a 10 anos de estudo, tendo no máximo finalizado o ensino fundamental, a taxa se apresentou nos seus mais elevados patamares, em média $49,7 \%$ maior que as taxas gerais de desocupação registradas na Tabela 1. Em magnitude menor, mas, ainda assim, acima da média geral, a desocupação afligiu o estrato de pessoas com tempo de estudo entre 11 e 14 anos, com taxas de 0,6 a 1,5 p.p. maiores.

Gráfico 1- Evolução da taxa de desocupação por faixas de anos de estudo - Brasil - 2001, 2005, 2009 e 2015

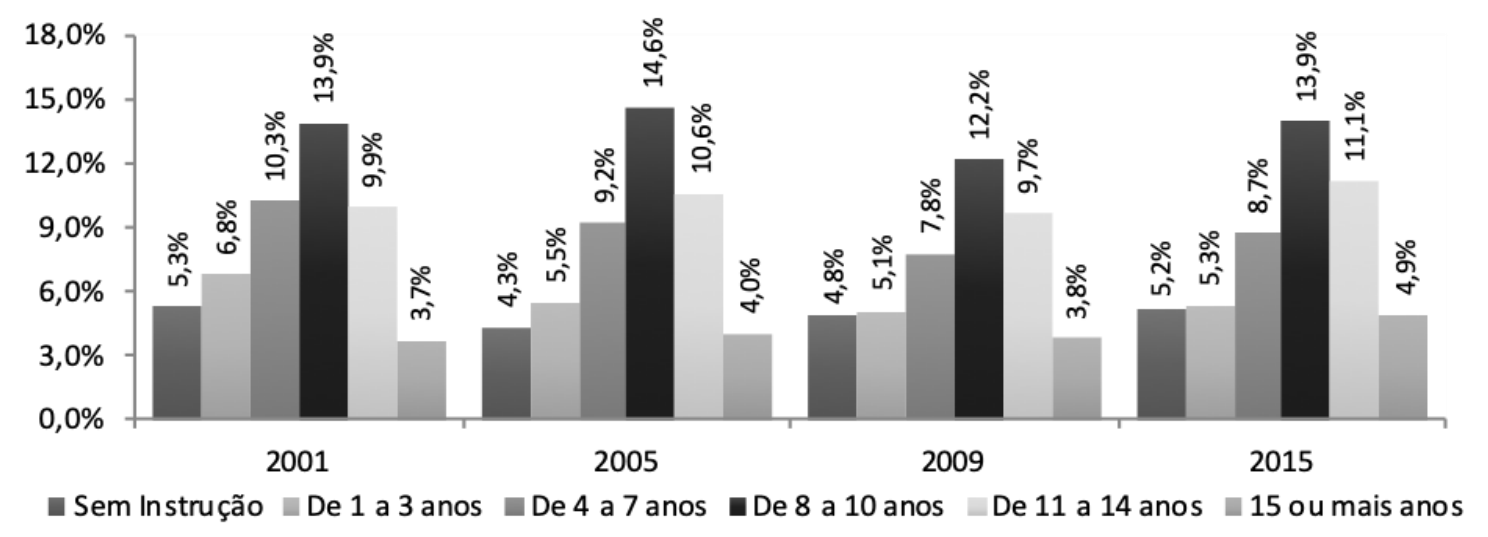

Fonte: IBGE/PNAD

A partir de outra perspectiva de análise, a do universo dos indivíduos ocupados, os dados da PNAD deixam clara a elevação da escolaridade desse grupo populacional (Gráfico 2).

Gráfico 2- Evolução da distribuição relativa da ocupação por faixas de anos de estudo - Brasil - 2001, 2005, 2009 e 2015

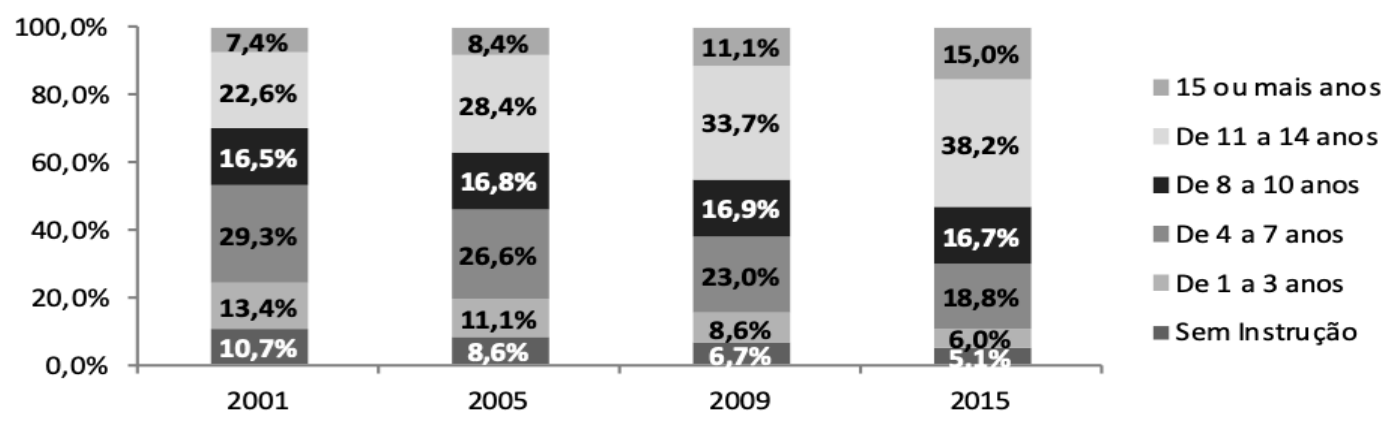

Fonte: IBGE/PNAD 
A parcela com 11 anos ou mais de estudo, que, no mínimo, finalizou o ensino médio, em 2001, abrangia menos de um terço do total (30,0\%); já em 2015, perfez mais da metade $(53,2 \%)$. Por outro lado, o subconjunto dos indivíduos com até 7 anos de estudo que, em 2001 , compunha $53,4 \%$ dos ocupados, registrou queda de $44,0 \%$, totalizando, no último ano analisado, $29,9 \%$.

Além desses fatos, é importante que sejam levadas em conta as possíveis posições em que se inseriram os trabalhadores no universo da ocupação. Isto porque cada vez mais, como será observado na sequência, um maior número de anos de estudo finalizados pode não representar garantia de inserção em uma posição desejada. Cada uma das cinco posições de ocupação mais frequentes, quando consideradas sob a perspectiva de faixas de anos de estudo, pode melhor revelar tal realidade.

\section{3 $O$ universo dos ocupados sob a ótica da posição na ocupação}

Ao se analisar a evolução da distribuição relativa da ocupação por posição no interior do seu conjunto, verifica-se que, dentre suas cinco mais significativas categorias empregado, doméstico, conta própria, empregador e não remunerado, entre os anos de 2001 a 2015, duas delas, quais sejam, empregado e conta própria, tiveram variações positivas (Gráfico 3).

Gráfico 3- Evolução da distribuição relativa da ocupação por posição ocupada - Brasil - 2001, 2005, 2009 e 2015

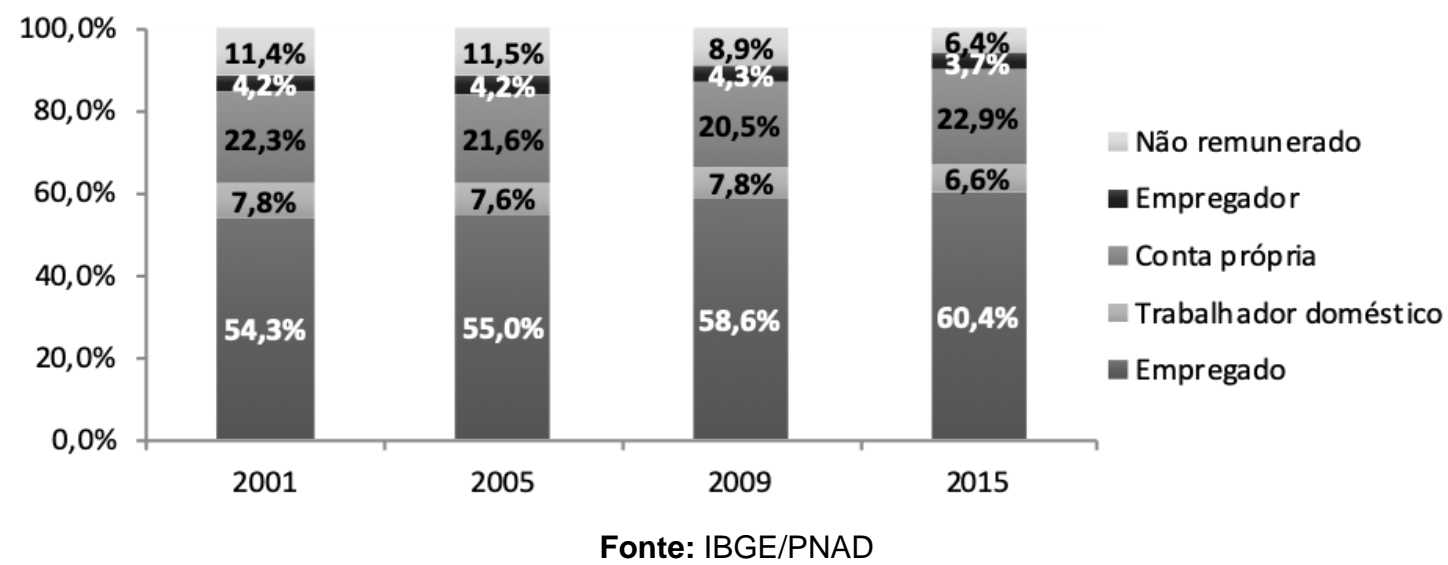

O conjunto dos empregados cresceu $11,2 \%$, saltando de $54,3 \%$ para $60,4 \%$; já o dos conta própria, 2,7\%, saindo de $22,3 \%$ para $22,9 \%$. Os das demais três posições sofreram redução relativa; a mais significativa se deu para o contingente dos não remunerados, que caiu $43,9 \%$; o dos trabalhadores domésticos diminuiu $15,4 \%$, e o dos empregadores, $11,9 \%$.

Lançando-se olhar sobre a composição do subconjunto dos empregados do ponto de vista das faixas de anos de estudo (Gráfico 4), observou-se significativas alterações durante o período analisado: reduções nas participações das faixas com até 10 anos de estudo e efeito inverso nos dois subconjuntos com maior carga de tempo de estudo. 
Gráfico 4 - Evolução da distribuição relativa da posição ocupada empregado por faixas de anos de estudos Brasil - 2001, 2005, 2009 e 2015

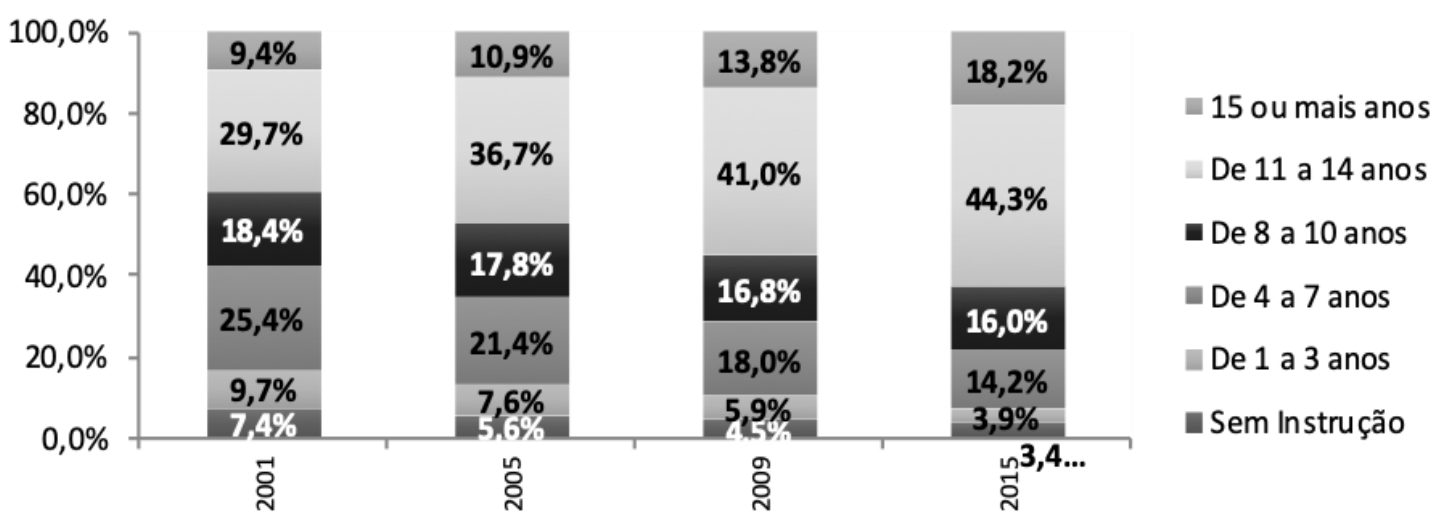

Fonte: IBGE/PNAD

De modo preciso, tem-se que a parcela com até 10 anos de estudo, que compunha $60,9 \%$ dos empregados, em 2001, passou, em 2015, a abranger 37,5\%. Já a dos indivíduos com 11 ou mais anos de estudo saltou de 39,1\% para 62,5\%. Este crescimento se deu em função das expansões de $93,6 \%$ da parcela com 15 ou mais anos de estudo e 49,0\% da de empregados com tempo de estudo de 11 a 14 anos.

Em relação à escolaridade entre os ocupados na posição de trabalhadores domésticos, esta deu claros sinais de elevação, já que, em 2001, apenas $7,0 \%$ possuía 11 ou mais anos de estudos e $23,6 \%$ apresentava-se com 8 anos ou mais. Quando feita esta mesma avaliação para 2015, vê-se que as faixas com 11 ou mais anos de estudo haviam mais que triplicado, perfazendo 24,3\%; a dos trabalhadores domésticos com 8 anos ou mais de estudo, a parcela quase que dobrou de tamanho, saltando de 23,6\%, em 2001, para o patamar de 46,7\% da força de trabalho doméstica em 2015 (Gráfico 5).

\begin{tabular}{r|r|c|c|c} 
Gráfico 5- Evolução da distribuição relativa da posição ocupada trabalhador doméstico por faixas de anos de \\
estudos
\end{tabular}

Fonte: IBGE/PNAD

Embora percentualmente ainda baixo, é importante destacar o surgimento estatístico do trabalhador doméstico de nível superior de escolaridade, com 15 ou mais anos de estudo, nesta que é comprovadamente uma das posições na ocupação em que as condições de trabalho se fazem mais precárias. Tal classe, que inexistia em 2001, apresentou-se, em 2015, abrangendo 1,6\% do subconjunto em questão (Gráfico 5).

Além do trabalhador doméstico, outra posição em que a precariedade do trabalho se faz presente em diversos dos seus aspectos é a do trabalhador por conta própria. Em geral, 
os trabalhadores por conta própria têm jornadas mais extensas, apresentam rendimentos inferiores àqueles que são empregados, não estão cobertos por boa parte dos institutos da seguridade social, não se encontram associados ou sindicalizados e suas condições de trabalho são altamente instáveis (PAMPLONA, 2001, p. 119). Entre suas atividades econômicas, uma das que, atualmente, melhor pode servir de exemplo desta realidade é a dos motoristas associados à Uber, com jornada de trabalho e remuneração flexíveis, inexistência de obrigatoriedade de contribuição para previdência social e total incerteza quanto à possibilidade de permanência na realização daquele serviço.

Entre 2001 e 2015, o subconjunto dos conta própria que apresentou uma tendência à queda até 2013, cresceu (Gráfico 3). O comportamento das variações da sua participação no global das ocupações, mesmo não apresentando alterações quantitativamente similares, seguiu a cada ano, quase sempre, a mesma direção da taxa de desocupação (Gráfico 6).

Gráfico 6- Evolução anual da taxa de desocupação e da participação da força de trabalho na posição na ocupação conta própria, Brasil, 2001-2015

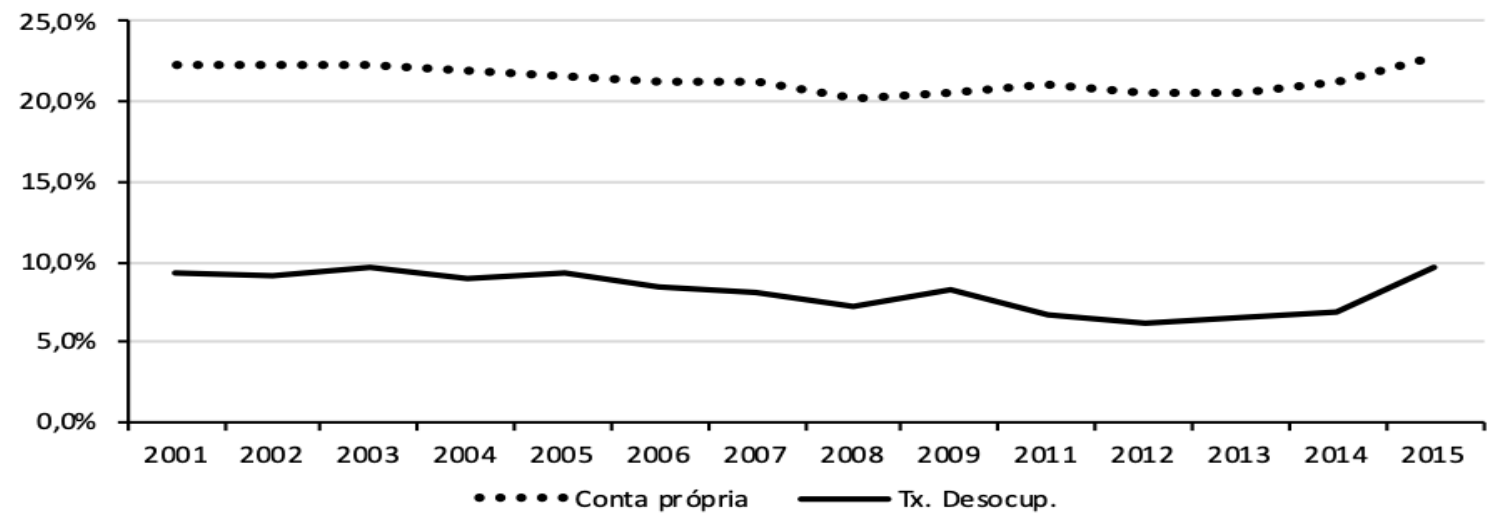

Fonte: elaboração própria

Em verdade, procedendo-se o teste de correlação entre os dados desses dois indicadores, para o período estudado, verificou-se forte relação $(0,817)$, positiva, entre a variação da desocupação e a participação da posição por conta própria na ocupação, permitindo-se afirmar que esse tipo de ocupação tende a crescer com elevações na taxa de desocupação, não sendo necessariamente o inverso verdadeiro, já que o crescimento da força de trabalho na posição de conta própria reduz a desocupação. Os dados refletem a realidade de que, quando o desemprego se alastra, as pessoas passam a ter mais dificuldade para garantir a sua reprodução material. Em função disso, muitas delas são compelidas a desenvolver alguma atividade produtiva por conta própria, especialmente no âmbito da informalidade, onde grassa a irregularidade da frequência de realização das atividades laborais e, consequentemente, dos rendimentos. Esta é, em verdade, uma das faces do processo de precarização do trabalho: camuflar o fenômeno do desemprego.

Analisando-se a composição da força de trabalho ocupada na posição conta própria a partir do ponto de vista das faixas de anos de estudo, pode-se observar que, entre 2001 e 2015, a parcela dos que tinham de 11 a 14 anos de estudo mais que dobrou, aumentando sua participação para $101,4 \%$. A daqueles com maior tempo de vida dedicada aos estudos cresceu 91,8\%, saltando de 4,9\% em 2001 para 9,4 em 2015 (Gráfico 7). 
Gráfico 7 - Evolução da distribuição relativa da posição ocupada conta própria por faixas de anos de estudos Brasil - 2001, 2005, 2009 e 2015

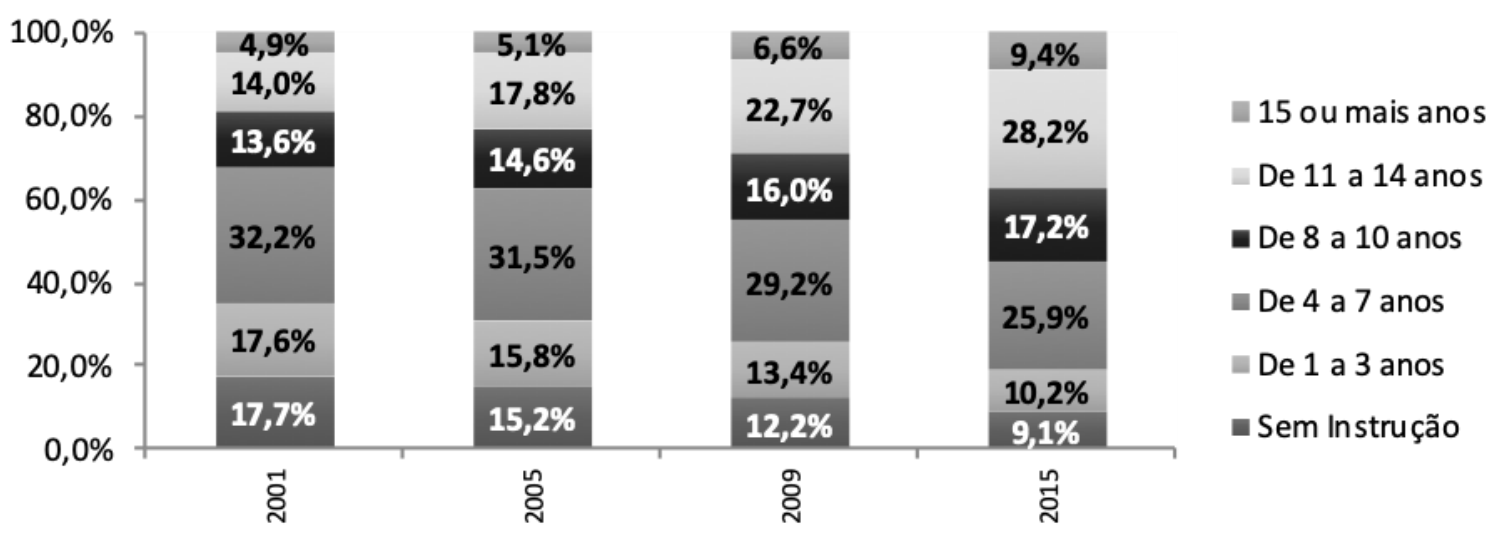

Fonte: IBGE/PNAD

Direcionando a leitura para a avaliação da evolução da categoria de posição na ocupação com menor participação relativa, a de empregador, sob a ótica do seu tempo de estudo, durante todo o período estudado, vê-se que ela reuniu os indivíduos com as melhores credenciais educacionais (Gráfico 8). Isso porque, mais da metade dos empregadores tinha no mínimo 11 anos de estudo em 2001 (51,8\%). Já em 2015, esta parcela havia aumentado para mais de 2/3 (69,4\%).

Gráfico 8 - Evolução da distribuição relativa da posição ocupada empregador por faixas de anos de estudos Brasil - 2001, 2005, 2009 e 2015

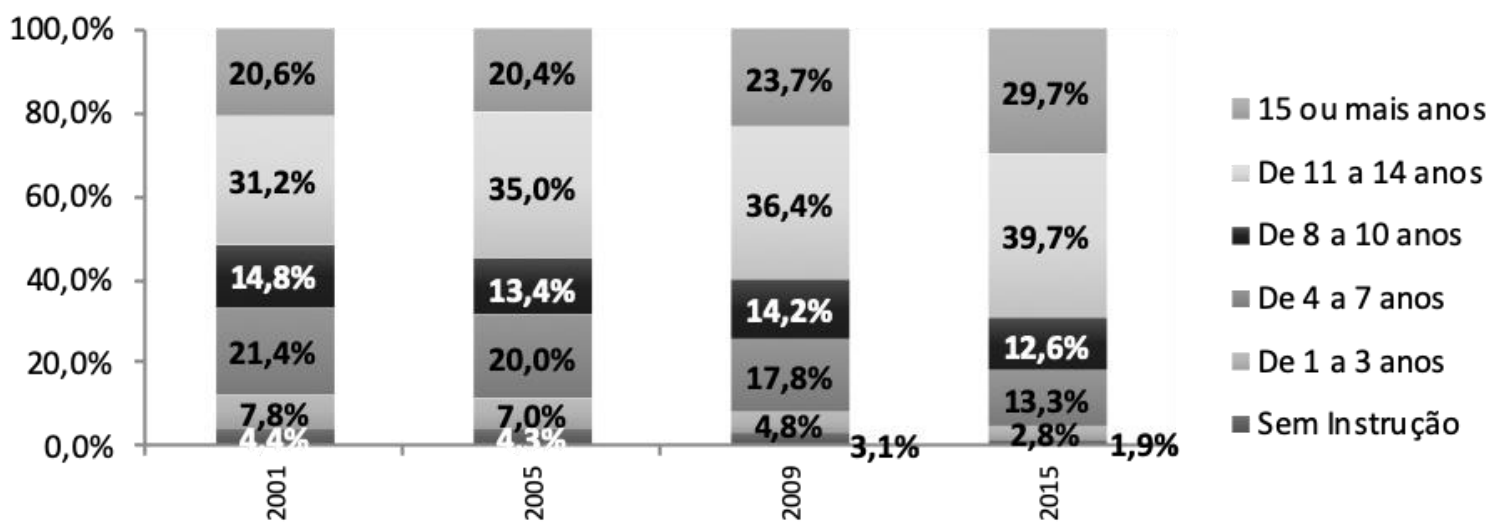

Fonte: IBGE/PNAD

Em relação à distribuição dos não remunerados por faixas de anos de estudo, embora tenha se verificado para o período uma elevação na participação das pessoas com mais tempo dedicado aos estudos, a grande maioria desses trabalhadores $(68,4 \%)$ tinha até 7 anos de estudo em 2015 (Gráfico 9). 
Gráfico 9- Evolução da distribuição relativa da posição ocupada não remunerado por faixas de anos de estudos - Brasil - 2001, 2005, 2009 e 2015

\begin{tabular}{|c|c|c|c|c|c|}
\hline $100,0 \%$ & $\begin{array}{c}0,7 \% \\
6,3 \% \\
10,3 \% \\
\end{array}$ & $\begin{array}{l}9,7 \% \\
11,7 \%\end{array}$ & $\begin{array}{l}1,5 \% \\
11,2 \%\end{array}$ & $\begin{array}{c}2,1 \% \\
14,1 \% \\
\end{array}$ & \\
\hline $80,0 \%$ & & & $13,9 \%$ & $15,2 \%$ & 15 ou mais anos \\
\hline $60,0 \%$ & $35,9 \%$ & $36,8 \%$ & $34,0 \%$ & $31,6 \%$ & $\begin{array}{l}\text { De } 11 \text { a } 14 \text { anos } \\
\text { De } 8 \text { a } 10 \text { anos }\end{array}$ \\
\hline $\begin{array}{l}40,0 \% \\
20,0 \%\end{array}$ & $25,4 \%$ & $23,1 \%$ & $19,2 \%$ & $18,4 \%$ & $\begin{array}{l}\text { De } 4 \text { a } 7 \text { anos } \\
\text { De } 1 \text { a } 3 \text { anos }\end{array}$ \\
\hline & $21,4 \%$ & $19,8 \%$ & $20,2 \%$ & $18,4 \%$ & - Sem In strução \\
\hline & స్ & ڤ్ & : & $\stackrel{n}{\tilde{N}}$ & \\
\hline
\end{tabular}

Fonte: IBGE/PNAD

Em 2001, essa fragilidade educacional em termos formais era ainda mais acentuada, posto que correspondia a $82,7 \%$ desse subconjunto dos ocupados. Para contrabalancear esse movimento, a parcela com 11 anos ou mais de estudo que representava $7,0 \%$ desses trabalhadores, em 2001, passou, em 2015, a responder por $16,2 \%$.

\subsection{A flexibilização do trabalho}

Dentre as transformações verificadas sobre a ocupação no Brasil durante a última década do século $X X$, podem ser destacadas a informalização e a flexibilização das formas de contratação do trabalho. No presente artigo, tendo por base a experiência de Schneider e Rodarte (2006, p. 82-88) e do IPEA, que, a partir de dados da PNAD, elaborou o indicador de grau de informalidade do trabalho (IPEADATA), denomina-se de ocupações flexibilizadas o conjunto das ocupações sem carteira assinada, conta própria, de produção para próprio consumo e não remuneradas, de forma a analisar, para o período de 2001 a 2015, como o processo da flexibilização do trabalho no Brasil se apresentou.

Observando-se a evolução da participação das ocupações flexibilizadas, verifica-se uma queda de $17,3 \%$ nos quinze primeiros anos deste século, saindo de 57,9\% das ocupações em 2001 para 47,9\% em 2015 (Tabela 3).

Tabela 3- Evolução da participação da ocupação flexibilizada no total da ocupação, Brasil - 2001, 2005, 2009 e 2015

\begin{tabular}{lrrrr}
\hline \multirow{2}{*}{ DISCRIMINAÇÃO } & \multicolumn{5}{c}{ Ano } \\
\cline { 2 - 5 } & \multicolumn{1}{c}{2001} & \multicolumn{1}{c}{2005} & \multicolumn{1}{c}{2009} & \multicolumn{1}{c}{2015} \\
\hline Ocupados & 76.936 .438 & 87.695 .271 & 93.783 .537 & 95.380 .483 \\
Ocupados flexibilizados & 44.533 .419 & 49.595 .688 & 48.289 .944 & 45.660 .410 \\
\% de Ocupação flexibilizada & $57,9 \%$ & $56,6 \%$ & $51,5 \%$ & $47,9 \%$ \\
\hline
\end{tabular}

Fonte: PNAD/IBGE, 2001-2009 e 2011-2015

Tal fato se deve às melhores condições de inserção decorrentes da queda verificada na desocupação até 2013, à intensificação da fiscalização do Ministério do Trabalho e Emprego (MTE) (SIMÃO, 2009), corroborada, a partir de 2014, pela implantação do Sistema de Escrituração Fiscal Digital, SPED Social ou eSocial. Este sistema 
informatizou e unificou por completo as declarações trabalhistas acessórias que são feitas pelos empregadores aos mais diversos órgãos governamentais, facilitando 0 processo de fiscalização do trabalho.

Alternando a leitura das ocupações flexibilizadas para o recorte por faixas de anos de estudo, verifica-se um grande crescimento da parcela percentual da força de trabalho com maior tempo de instrução formal (Tabela 4). Os indivíduos com 11 a 14 anos de estudo submetidos a condições flexíveis de trabalho aumentaram 103,8\% sua participação entre 2001 e 2015. Simultaneamente, a força de trabalho com maior escolaridade ampliou sua fatia de 3,4\% para 8,0\% - incremento de 135,3\%.

Tabela 4- Evolução da distribuição da ocupação flexibilizada por faixas de anos de estudo, Brasil - 2001, 2005, 2009 e 2015

\begin{tabular}{lrrrr}
\hline \multirow{2}{*}{ Anos de Estudo } & \multicolumn{4}{c}{ Ano } \\
\cline { 2 - 5 } & 2001 & 2005 & 2009 & \multicolumn{2}{c}{$\mathbf{2 0 1 5}$} \\
\hline Total & $100,0 \%$ & $100,0 \%$ & $100,0 \%$ & $100,0 \%$ \\
Sem Instrução & $16,6 \%$ & $14,3 \%$ & $12,3 \%$ & $9,8 \%$ \\
De 1 a 3 anos & $18,5 \%$ & $16,0 \%$ & $13,4 \%$ & $10,7 \%$ \\
De 4 a 7 anos & $33,5 \%$ & $32,3 \%$ & $29,7 \%$ & $26,1 \%$ \\
De 8 a 10 anos & $14,3 \%$ & $16,1 \%$ & $17,5 \%$ & $18,2 \%$ \\
De 11 a 14 anos & $13,3 \%$ & $17,2 \%$ & $21,6 \%$ & $27,1 \%$ \\
15 ou mais anos & $3,4 \%$ & $3,9 \%$ & $5,2 \%$ & $8,0 \%$ \\
Não determinado & $0,4 \%$ & $0,3 \%$ & $0,2 \%$ & $0,2 \%$ \\
\hline
\end{tabular}

Fonte: PNAD/IBGE, 2001-2009 e 2011-2015

\subsection{A renda do trabalhador do ponto de vista do tempo de estudo}

No que tange às condições de trabalho, a renda (preço da força de trabalho) é, certamente, $\mathrm{O}$ indicador mais significativo. No período de 2001 a 2015, a classe trabalhadora obteve em média, uma elevação de $33,3 \%$ (ou 1,9\% a.a.) do seu rendimento real mensal. Tal processo de crescimento se deu primordialmente a partir de 2005 (Tabela 5).

Tabela 5 - Evolução anual do rendimento real médio mensal, Brasil - 2001/2015

\begin{tabular}{|c|c|c|}
\hline \multirow{2}{*}{ Ano } & \multicolumn{2}{|c|}{ Rendimento Médio } \\
\hline & Nominal & Real (1) \\
\hline 2001 & $\mathrm{R} \$ 362,28$ & $\mathrm{R} \$ 903,87$ \\
\hline 2005 & $\mathrm{R} \$ 521,28$ & $\mathrm{R} \$ 927,13$ \\
\hline 2009 & $\mathrm{R} \$ 733,90$ & R\$ $1.096,82$ \\
\hline 2015 & $\mathrm{R} \$ 1.204,71$ & $\mathrm{R} \$ 1.204,71$ \\
\hline
\end{tabular}

Fonte: PNAD/IBGE, 2001, 2005, 2009 e 2015

(1) A preços de 2015, com base no IPCA/IBGE

A evolução do rendimento médio mensal real quando analisada a partir do ponto de vista do tempo de estudo dos trabalhadores apresenta pelo menos dois fatos curiosos. $O$ primeiro refere-se à queda das rendas médias das duas classes com mais tempo de estudo (Tabela 6). 
Tabela 6 - Evolução anual do rendimento real médio mensal por faixas de anos de estudo, Brasil - 2001 a 2015

\begin{tabular}{ccccccc}
\hline \multirow{2}{*}{ Ano } & \multicolumn{5}{c}{ Anosde Estudo } \\
\cline { 2 - 7 } & Sem Instrução & De 1 a 3 anos & De 4 a 7 anos & De 8 a 10 anos & De 11 a 14 anos & 15 anosou mais \\
\hline 2001 & $\mathrm{R} \$ 422,97$ & $\mathrm{R} \$ 384,70$ & $\mathrm{R} \$ 517,78$ & $\mathrm{R} \$ 734,16$ & $\mathrm{R} \$ 1.515,28$ & $\mathrm{R} \$ 5.098,36$ \\
2005 & $\mathrm{R} \$ 493,71$ & $\mathrm{R} \$ 426,96$ & $\mathrm{R} \$ 520,55$ & $\mathrm{R} \$ 664,21$ & $\mathrm{R} \$ 1.329,39$ & $\mathrm{R} \$ 4.549,07$ \\
2009 & $\mathrm{R} \$ 639,41$ & $\mathrm{R} \$ 502,72$ & $\mathrm{R} \$ 610,27$ & $\mathrm{R} \$ 762,76$ & $\mathrm{R} \$ 1.380,51$ & $\mathrm{R} \$ 4.328,41$ \\
2015 & $\mathrm{R} \$ 784,48$ & $\mathrm{R} \$ 583,33$ & $\mathrm{R} \$ 670,42$ & $\mathrm{R} \$ 776,61$ & $\mathrm{R} \$ 1.333,01$ & $\mathrm{R} \$ 4.008,55$ \\
\hline
\end{tabular}

Fonte: IBGE/PNAD

A força de trabalho com 15 ou mais anos de estudo, que recebia em média $R \$ 5.098,36$ por mês, em 2001, fechou o ano de 2015 com renda mensal média real de $\mathrm{R} \$ 4.008,55$ - uma redução de $21,4 \%$ do seu poder de compra. Movimento em direção similar, mas de queda menos intensa, ocorreu em relação aos proventos médios mensais médios daqueles que completaram de 11 a 14 anos de estudo, que decresceram 12,0\%, entre 2001 e 2015.

No extremo oposto das classes desse recorte, entre os trabalhadores sem instrução, em função da política de valorização do salário mínimo, o rendimento médio mensal teve seu maior crescimento no período em análise (85,3\%), fazendo com que, em 2015, uma pessoa com menos de um ano de estudo ganhasse em média pouco mais que os trabalhadores com até 10 anos de estudo (0,9\%). Naquele ano, um trabalhador sem instrução recebia em média 17,0\% a mais que o trabalhador com 4 a 7 anos concluídos de estudo. Sua renda também era $34,5 \%$ superior à do trabalhador com 1 a 3 anos de estudos.

Importante destacar as grandes diferenças em termos de rendimento que existem entre a força de trabalho com até 10 anos de estudo e os trabalhadores com tempo de estudo de 11 a 14 anos, bem como dessa classe para aquela que the é superior. No ano de 2015, em média, o indivíduo com ensino médio finalizado ou próximo desse patamar recebeu em torno de $71,5 \%$ a mais que aqueles indivíduos com até 10 anos de estudo. No mesmo ano, trabalhadores que ingressaram e terminaram o ensino superior obtiveram proventos médios mensais três vezes maior que aqueles finalizaram até o $14^{\circ}$ ano de estudo.

Quando se leva em consideração o processo histórico de formação social do Brasil e do seu mercado de trabalho, marcados pela herança escravista e pela negligência em relação à qualificação da força de trabalho, é imperativo o destaque do fenômeno da intensa elevação da escolaridade da força laboral brasileira no início do século XXI. Para uma maior chance de inserção entre os ocupados, a chamada economia de mercado força que o indivíduo busque por qualificação, sem, contudo, garantir-lhe a inserção desejada. Por isso, verifica-se uma realidade que, em alguns aspectos, contraria as expectativas constituídas de que uma maior dedicação de tempo aos estudos seria sinônimo de uma melhor inserção no mercado de trabalho. Observando-se a força de trabalho sob as perspectivas do desemprego, da precarização dos contratos de trabalho e da renda da população ocupada, verificaram-se fatos surpreendentes ao senso comum.

Efetivamente, o universo das ocupações passou a ser majoritariamente constituído por pessoas com pelo menos o ensino médio concluído. Tal fato resulta naturalmente, dentre outros motivos, da ampliação da oferta de força de trabalho com tal característica. Os indivíduos com 11 a 14 anos concluídos de estudo, em especial, enfrentaram uma maior 
concorrência, uma taxa de desocupação acima da média geral, flexibilização dos vínculos contratuais de trabalho e consequente tendência à queda da renda média.

O desemprego se fez efetivamente menor entre os trabalhadores que ingressaram no ensino superior. A renda desta classe é em média significativamente maior que a média geral $(232,8 \%)$, embora tenha apresentado, nos quinze anos analisados, uma queda que, em termos absolutos (menos $\mathrm{R} \$ 1.089,82$ ), se aproximou da renda média da faixa que lhe é imediatamente inferior $(\mathrm{R} \$ 1.333,01)$.

Dentre as três faixas com maior tempo de estudo, apenas a dos trabalhadores com 15 ou mais anos de estudo apresentou em média taxa de desocupação abaixo da média geral entre 2001 e 2015. As outras duas, que compreendem os indivíduos com 8 a 14 anos de estudo, foram os que mais sofreram com o desemprego; mais que os trabalhadores sem instrução ou que aqueles que finalizaram até 7 anos de estudos.

A estratégia de elevação das credenciais escolares por parte dos trabalhadores se traduz em mais ampla inserção na ocupação e maiores rendas médias. Estas, entretanto, embora mais elevadas, decrescem de forma significativa nos dois estratos com credenciais escolares maiores, em que também crescem os vínculos flexibilizados de trabalho. Assim que, hoje, no Brasil, não necessariamente, mais estudo se transforma em menor taxa de desemprego ou maior segurança social advinda dos contratos de trabalho.

Alguns fatos demonstrados pelos dados da PNAD que chamaram a atenção estão relacionados à classe dos trabalhadores sem instrução. No âmbito deste subgrupo populacional, a taxa de desocupação foi a segunda menor, a maior valorização da média salarial em termos absolutos e a participação entre as ocupações flexibilizadas foi a segunda menor.

\section{IMPACTOS VERIFICADOS E IMPACTOS TEMIDOS SOBRE O TRABALHO}

Desde a Revolução Industrial até os dias atuais, os avanços tecnológicos geram temor e questionamentos em relação a seus efeitos sobre o trabalho dos seres humanos. Como nos momentos das críticas invenções do motor a vapor, dos motores a combustão, do uso da energia elétrica, dos transportes e das comunicações velozes, as novidades hodiernas guardam reconhecido potencial de reconfiguração dos processos produtivos, com ganhos significativos de produtividade no trabalho, acompanhados, consequentemente, de uma redução da necessidade técnica de determinadas habilidades humanas incorporadas pelas máquinas. Como resultado, tem-se a expectativa de que o mercado de trabalho apresente novas mudanças, com aumento significativo do desemprego estrutural e redesenho da demanda por força de trabalho.

A despeito desse justificável temor, a abater trabalhadores dos mais distintos níveis de qualificação técnica e profissões, Teles e Caldas (2019) chamam a atenção para o fato de tal medo vincular-se a um evento futuro que, embora possível, ainda se encontra indefinido no tempo e no espaço, passível de sofrer influências de natureza sociopolítica. Previsões nesta direção de um desemprego estrutural de grandes proporções feitas tanto por Marx (1996) em sua crítica a teoria da compensação, quanto por Keynes (1963) nas suas preocupações com nossos netos, não ocorreram, embora sigam sendo recorrentes "antecipações semelhantes de um desemprego tecnológico massivo [...] no atual debate sobre o 'futuro do trabalho"' (CALDAS; TELES, 2019, p. 32). 
Neste sentido, é interessante destacar uma colocação feita por estes autores que corrobora para a concepção do embrião de proposta de política pública de educação que aqui será apresentada. Afirmam eles que:

\begin{abstract}
O julgamento que possamos fazer dos futuros que nos são propostos, e a escolha daqueles que desejamos (ou queremos evitar) para os nossos netos, dependem não só de antecipações carregadas de incerteza quanto ao impacto que as 'novas' tecnologias poderão vir a ter no emprego, mas, fundamentalmente, do modo como concebemos o trabalho humano e as máquinas. Concepções do trabalho distintas transportam consigo implicações políticas opostas (CALDAS; TELES, 2019, p. 32).
\end{abstract}

Assim sendo, já no presente, por razões caracteristicamente não tecnológicas, mas essencialmente políticas, elevado desemprego estrutural, drástica redução da proteção social, queda persistente da renda laboral e precarização das condições do trabalho configuram o mundo contemporâneo (TELES; CALDAS, 2019).

Nesse ambiente bastante adverso para a classe que vive do trabalho, é atribuído ao surgimento de empresas que dão forma aos fenômenos da Gig-economy, sharing economy, crowdsourcing, on-demand economy, plataformização, uberização e outras denominações um caráter revolucionário. As "grandes" transformações causadas pelas indevidamente chamadas empresas plataformas seriam, para muitos, sinais inquestionáveis de que o emprego se encontra em extinção.

Entretanto, deixando esta reiterada retórica de lado e analisando as implicações práticas das inovações em questão, em verdade, pode-se afirmar que o efeito delas sobre o processo produtivo recaem quase que exclusivamente sobre o/a trabalhador/a. A título de exemplo, a Uber, em termos técnicos, não alterou a forma nuclear do serviço de como um(uma) motorista busca um passageiro e o translada de um ponto geográfico a outro (TELES; CALDAS, 2019). A mudança principal reside nas relações que se estabelecem entre o prestador (empresa), o/a executor(a) (motorista) e o/a contratante (passageiro/a) do serviço. O poder por ser exercido por cada uma das partes durante o tempo que a relação social se concretiza revela claramente que a plataforma digital não é a empresa, mas sim uma ferramenta por ela utilizada para realizar, primeiramente, a comunicação entre o/a contratante e a Uber, e entre esta e o/a motorista; em seguida, monitorar a prestação do serviço; e, depois, avaliar executor(a) e contratante. Adicionalmente, o valor do serviço prestado e a parcela que a cada um cabe são definidos pela Uber. Por fim, a empresa de serviços de transporte tem o poder de, a qualquer momento, sem necessidade de justificativas claras, desligar os motoristas nela cadastrados. De forma análoga, com algumas variações decorrentes da natureza do serviço ofertado, relações similares de poder são exercidas por empresas de serviços de delivery, de aluguéis de imóveis, de tradução, etc. Dessa forma, a plataforma digital constitui factualmente uma ferramenta de gestão do negócio e do trabalho (FILGUEIRAS; CAVALCANTE, 2018; ANTUNES; FILGUEIRAS, 2019). Os algoritmos nelas programados registram, analisam e direcionam as tomadas decisão tendo por norte os objetivos da empresa. Como ferramenta que é, está longe de representar uma inovação radical na forma de produzir um bem ou prestar um serviço.

Se por um lado, nesse contexto, a tecnologia possibilita o desenvolvimento de novas formas de organização e gestão do trabalho, por outro, a quase nula regulamentação da 
atividade, que pode ser lida como um laissez faire, laissez aller, laissez passer6, gera impactos degradantes sobre as condições de trabalho e vida da classe trabalhadora. Sem maiores direitos a serem respeitados pelas empresas, os custos e riscos inerentes a toda a prestação do serviço recaem sobre os trabalhadores (SLEE, 2017). Com jornada e remuneração do trabalho flexíveis, trabalha-se cada vez mais, para se receber cada vez menos (ANTUNES, FILGUEIRAS, 2019).

\section{Municiando a desregulamentação do trabalho com "NOvos" ARGUMENTOS}

A recente história dos estudos do trabalho registra dois momentos em que foram propostas teorias que sugerem o desaparecimento dos trabalhadores como classe social e categoria central de análise da dinâmica do modo de vida e produção capitalista. O primeiro deles, nos anos 1980, quando Gorz (1982) apresentou seu "Adeus ao proletariado" e Offe (1989) pôs em xeque a centralidade do trabalho como categoria chave da sociologia. Nesse primeiro debate, tal proposição encontrou, nos estudos apresentados a partir de meados dos anos 1990 por Antunes (2006; 2009), seu contraponto, indicando ser fundamental compreender as transformações pelas quais passava a classe-que-vive-do-trabalho.

O segundo momento, muito recente, nasce da proposta de Standing (2015) que advoga estar em processo a formação de uma nova classe social, o precariado, reflexo da construção da sociedade global de mercado que resultaria numa nova estrutura de classes sociais, na qual a classe trabalhadora haveria deixado de existir como unidade de classe, se repartindo em distintas novas classes. Mais de duas décadas depois do seu Adeus ao proletariado?, Antunes (2018, p. 63-64), após analisar as sugestões conceituais de Standing, afirma:

\section{[...] estamos desafiados a compreender sua nova polissemia [da classe trabalhadora], sua nova morfologia, cujo elemento mais visível é o desenho multifacetado, que faz aflorar tantas transversalidades entre classe, geração, gênero, etnia etc. [...] Essa nova morfologia compreende não só o operariado herdeiro da era taylorista e fordista, [...] mas deve incluir também os novos proletários precarizados de serviços, parte integrante e crescente da classe-que-vive-do-trabalho.}

Neste mesmo sentido, Filgueiras e Cavalcanti (2018), avaliando a proposta teórica de Standing, mostram que esta é fruto de uma relativa superficialidade da observação da realidade contemporânea do trabalho que, no campo das aparências, visto pela perspectiva legal do vínculo contratual entre capital e trabalho, da delimitação da jornada de trabalho e da definição prévia dos valores salariais, parecem desconstruir a classe trabalhadora. Entretanto, se observadas suas características essenciais de assalariamento, subordinação e consequente assimetria de poder entre capital e trabalho, verifica-se que parcela significativa das modificações vivenciadas pelos trabalhadores resultam da flexibilização dos parâmetros definidores da relação contratual, que inexistiam no início da formação do mercado de trabalho com o advento da Revolução Industrial e que foram conquistados paulatinamente, ao longo de cerca de 150 anos.

\footnotetext{
6 Deixai fazer, deixai ir, deixai passar, mote do liberalismo econômico clássico, herdado pela escola
} neoclássica da economia. 
Os referidos pesquisadores enfatizam que a pseudo inexorabilidade do processo de desaparecimento da regulação de proteção da classe trabalhadora se alimenta da narrativa do "novo adeus à classe trabalhadora". Diante de uma retomada do discurso de redesenho da estrutura de classes sociais no atual contexto de uso de novo ferramental tecnológico para gestão do trabalho, é argumentado que, a despeito dos esforços no sentido de negar relações de emprego, as novas formas de trabalho seguem predominantemente sendo assalariadas, com remuneração não mais pré-definida por uma jornada de trabalho, mas sim para cada microtarefa realizada, tomando, assim, a forma definida por Marx como sendo o salário por peça. Admitindo que existem, sim, mudanças na gestão do trabalho por parte das empresas, tal processo integra estratégias de dissimulação da relação salarial com vistas a reduzir as alternativas de limitação à exploração do trabalho. Isto porque, como afirma Marx (2017, p. 624), "dado o salário por peça, é natural que o interesse do trabalhador seja o de empregar sua força de trabalho o mais intensamente possível, o que facilita ao capitalista a elevação do grau normal de intensidade".

Para demonstrar tal fato, são apresentados quatro argumentos centrais. O primeiro, com bases em séries estatísticas abrangendo mais de duas décadas, assevera que o trabalho assalariado cresceu por todo o mundo, de acordo com dados agregados que cobrem as últimas décadas. O segundo afirma que as chamadas novas formas de trabalho, que tratam os trabalhadores como produtores independentes, parceiros, associados, etc., não passam de estratégias adotadas de gestão do trabalho, incrementando a flexibilidade dos seus institutos e sua precariedade, negando a relação de emprego em si mesma, para minar a imposição social de limites à exploração do trabalho. O terceiro, também estatisticamente lastreado, indica que as variações sobre o emprego por conta própria real ou disfarçado está fortemente vinculado à performance do mercado de trabalho e às regulações sociais do trabalho. O quarto denuncia que a narrativa do "novo adeus ao proletariado" fortalece a estratégia de ganho de poder do capital, tornando o trabalho mais precário e sem condição de se opor aos atuais patamares de exploração, legitimando, assim, formas precárias de contratação e gestão de trabalho, por apresenta-las como inexoráveis.

Esse último argumento acaba por encorajar e ser encorajado pela ideia de que a estrutura de classes mudou com o surgimento da nova classe do precariado ou 0 surgimento de uma "zona cinzenta" no mercado de trabalho. Embora estas proposições teóricas se apresentem a partir de distintas perspectivas políticas, ambas defendem que há uma redução geral do trabalho assalariado, que teria sido substituído por outros tipos de trabalho ou mesmo por outras classes.

\section{CONSIDERACÕES FinAIS}

A proposta apresentada pelo Banco Mundial sob influência das ideias propugnadas pela Teoria do Capital Humano, em linhas gerais, sugere que o problema do desemprego, a ser causado pela adoção de novas tecnologias de produção, possa ser contornado com medidas dentre as quais destaca-se a educação, a formação técnica e a qualificação para o trabalho. Em sentido contrário à orientação dada, os dados da PNAD referentes à inserção dos trabalhadores no mercado de trabalho brasileiro entre 2001 e 2015, vistos a partir da perspectiva dos anos de estudo, demonstraram que o conjunto da força de trabalho brasileira, embora tenha elevado suas credenciais educacionais, não teve 
garantido para boa parte dos trabalhadores um melhor posicionamento em nessa instância social.

Esta realidade pode ser vista como oportunidade para se refletir sobre o papel da educação na formação dos seres sociais que compõem a classe-que-vive-do-trabalho no Brasil. Se hoje seus efeitos se afastam daquilo que originalmente se esperava (mais elevado bem estar para o trabalhador), que alternativas existem para que o objetivo de melhoria da qualidade de vida da população por meio do trabalho seja alcançado?

A partir dessa realidade, é possível identificar a necessidade de se repensar as funções sociais do processo educativo, trazendo como questão final a proposta de se refletir em que medida a educação não está sendo pensada tendo por finalidade quase que única a formação para o mundo do trabalho, em detrimento da formação do ser social que, além de trabalhar na produção de mercadorias e na prestação de serviços, também deve exercer função social e política ativa. E se ao invés de serem vistos exclusivamente como indivíduos trabalhadores, detentores cada um de uma parcela de capital humano que lhe deverá ser fonte geradora de renda por meio do trabalho, fosse observado o coletivo de seres humanos interdependentes entre si?

Nessa perspectiva, além de uma formação técnica, não seria importante que a população tivesse a oportunidade de desenvolver, no processo educacional formal, desde os anos iniciais de formação, sua compreensão crítica sobre seu processo histórico de formação social? Sobre o modo como se encontra organizada a sociedade à qual pertence de forma a se reproduzir? Sobre os efeitos na própria sociedade dessa sua forma de reprodução da vida social?

\section{REFERÊNCIAS}

ALVES, Giovanni. Dimensões da Reestruturação Produtiva: ensaios de sociologia do trabalho / Giovanni Alves. 2a edição. Londrina: Praxis; Bauru: Canal 6, 2007. Disponível em: http://xa.yimg.com/kq/groups/21224389/446627105/name/DRP.pdf. Acesso em: 13 out. 2017.

ANTUNES, Ricardo. $O$ caracol e sua concha: ensaios sobre a nova morfologia do trabalho. São Paulo: Boitempo, 2005.

ANTUNES, Ricardo. Adeus ao trabalho? ensaio sobre as metamorfoses e a centralidade do mundo do trabalho. 15. ed. São Paulo: Cortez, 2006.

ANTUNES, Ricardo. Os sentidos do trabalho: ensaio sobre a afirmação e a negação do trabalho. São Paulo: Boitempo, 2009. (Coleção Mundo do Trabalho).

ANTUNES, Ricardo.O privilégio da servidão: o novo proletariado de serviços na era digital. São Paulo: Boitempo, 2018. (Coleção Mundo do Trabalho).

ANTUNES, Ricardo; FILGUEIRAS, Vitor A.. Livre ou subordinado? Pesquisadores mostram como apps controlam entregador. Blog do Sakamoto, 2019. Disponível em: https://blogdosakamoto.blogosfera.uol.com.br/2019/12/13/livres-ou-vigiados-veja-11-medidas-de-appspara-controlar-entregadores/. Acesso em: 13 dez. 2019.

CALDAS, José C.; TELES, Nuno. Tecnologia, Trabalho e Emprego: das controvérsias do passado na economia política aos futuros possíveis. Cadernos do Observatório. Centro de Estudos Sociais, Universidade Coimbra, 2019. Disponível em: https://www.ces.uc.pt/observatorios/crisalt/?id=6522\&pag=9331. Acesso em: 07/12/2019.

FILGUEIRAS, Vitor; CAVALCANTE, Sávio. What has changed: a new Farewell to the Working Class? Mimeo, 2018.

GORZ, André. Adeus ao proletariado: para além do socialismo. Rio de Janeiro. Forense Universitária, 1980. 
KEYNES, John M.. Economic Possibilities for our Grandchildren. Essays in Persuasion, New York: W.W.Norton \& Co., 1963, pp. 358-373.

MARX, Karl. O capital: crítica da economia política. São Paulo: Nova Cultural, 1996. (Coleção Os Economistas).

MARX, Karl. O capital: crítica da economia política: livro I: o processo de produção do capital / Karl Marx; tradução Rubens Enderle. - 2ª ed. - São Paulo: Boitempo, 2017.

OFFE, C.; HINRICHS, K. Economia social do mercado de trabalho: diferencial primário e secundário de poder. In: OFFE, C. Trabalho e sociedade: problemas estruturais e perspectivas para o futuro da sociedade do trabalho. Rio de Janeiro: Tempo Brasileiro, 1989. v. 1. (Biblioteca Tempo Universitário n. 85. Série estudos alemães).

OFFE, Claus. Trabalho: a categoria sociológica chave? In: Capitalismo desorganizado. Transformações contemporâneas do trabalho e da política. São Paulo: Brasiliense, 1989. p. 167-197.

POCHMANN, Marcio. Raízes da grave crise do emprego no Brasil. In. O Trabalho no Século XXI. Sindicato dos Bancários da Bahia, 2002.

POCHMANN, Marcio. O emprego no desenvolvimento da nação / Marcio Pochmann. - São Paulo: Boitempo, 2008.

SCHNEIDER, Eduardo M.; RODARTE, Mario Marcos S. Evolução do mercado de trabalho metropolitano - entre meados das décadas de 1990 e 2000. São Paulo em Perspectiva, v. 20, n. 4, p. 74102, out./dez. 2006. Disponível em: http://produtos.seade.gov.br/produtos/spp/v20n04/v20n04_06.pdf. Acesso em: 20 out. 2017.

SIMÃO, Anna Rosa Alux. Sistema de vigilância e fiscalização do trabalho no Brasil - efeitos sobre a expansão do emprego formal no período 1999-2007. In: MERCADO de Trabalho - conjuntura e análise, IPEA, maio/2009. Disponível em: http://ipea.gov.br/agencia/images/stories/PDFs/mercadodetrabalho/03_NT2Anna_Simao.pdf . Acesso em: 12 fev. 2018.

SLEE, Tom. Uberização: a nova onda do trabalho precarizado; tradução de João Peres; notas da edição Tadeu Breda, João Peres. São Paulo: Elefante, 2017.

STANDING, Guy. The Precariat and Class Struggle. RCCS Annual Review [Online], 7 | 2015. Disponível em: http://rccsar.revues.org/585. Acesso em: 15/08/2019. DOI : 10.4000/rccsar.585.

TELES, Nuno; CALDAS, José C.. Tecnologia e Trabalho no século XXI: uma proposta de abordagem. Cadernos do Observatório. Centro de Estudos Sociais, Universidade Coimbra, 2019. Disponível em: https://www.ces.uc.pt/observatorios/crisalt/?id=6522\&pag=9331. Acesso em:28/11/2019.

Data da submissão: 20/12/2019

Data da aprovação: 14/05/2020 